\title{
Pelvic and acetabular fractures
}

\author{
W. Lehmann
}

Received: 6 August 2012/Accepted: 2 September 2012/Published online: 16 October 2012

(c) Springer-Verlag 2012

Dear colleagues,

The focus of this issue is the treatment of pelvic and acetabular fractures. The spectrum of these injuries varies, ranging from simple non-displaced fractures to highly unstable complex injuries that can be extremely challenging in terms of clinical management, surgical intervention and prevention of residual functional disability. Moreover, there has been an increase in pelvic injuries in Europe, which can be attributed to the changing age structure of the European population, with an increase of middle-aged and advancedage people. Growing age also impacts the origin and causes of those fractures; whereas previously young people suffered injury of the pelvis or acetabulum due to high-energy trauma, we see an increasing number of patients with insufficiency fractures of the sacrum or acetabular fractures after a trivial trauma. On the other hand, the progress in the treatment of pelvic fractures over the last two decades has undoubtedly led to a substantial improvement in the outcome of those patients.

The following papers focus on specific aspects in the diagnosis and management of pelvic fractures. Keel et al. [1] provide an overview of some important developments in pelvic surgery. Rommens et al. [2] discuss specific aspects that arise in fractures of the pelvis in the older patient. In addition to this work, the article by Rickman et al. [3] deals with the management of complex acetabular fractures in the

Dedicated to Professor Johannes M. Rueger's 60th Birthday.

W. Lehmann ( $\square)$

Department of Trauma, Hand and Reconstructive Surgery,

University Medical Center Hamburg-Eppendorf,

Hamburg, Germany

e-mail:wlehmann@uke.de elderly. Lehmann et al. [4] give an overview of the handling of spinopelvic dissociations. These authors would like to take the opportunity to dedicate this issue to the 60th anniversary of Professor Johannes M. Rueger.

Johannes M. Rueger was born on 28 September 1952 in Frankfurt/Main, Germany. He studied in Tübingen, Mainz and Berlin, and graduated in 1978. After a phase of orientation in which he received training in anaesthesia and urology, Professor Rueger passed, in 1979, the United States Medical Licensing Examination and started his residency in the Department of Surgery, University of Louisville, KY, USA. In 1981, he moved to the University Hospital of Frankfurt, where he received further training in the Department of Trauma, Hand and Reconstructive Surgery (Director Professor A. Pannicke). In 1990, he completed his habilitation on bone substitute materials. For this work, he was awarded several times. In 1991, he was appointed to Senior Consultant in Frankfurt. Clinically, pelvic and acetabular surgery was his particular passion early on.

In 1992, he worked as a visiting physician at the University of California under Professor J. Matta. In 1998, he was appointed to the Chair of the Department of Traumatology at the University Hospital Hamburg-Eppendorf. He was the successor to Professor Jungbluth, who led the department as one of the first German Professors for trauma surgery in Germany. Under the direction of Professor Rueger, the clinic expanded constantly, especially with a focus on the treatment of pelvic injuries. He is, for many years, faculty member of the Matta Pelvic Courses in Los Angeles, CA, USA, as well as pelvic Letournel Institute Courses in Paris, France, and introduced his own European Pelvic Course in Hamburg, Germany. His passion for pelvic surgery is still ongoing. We wish Professor Rueger on his 60th Birthday optimal health and as much creative energy to 
continue the burning passion for trauma and emergency surgery.

\section{References}

1. Keel MJB, Ecker TM, Siebenrock K-A, Bastian JD. Rationales for the bernese approaches in acetabular surgery. Eur J Trauma Emerg Surg. 2012. doi:10.1007/s00068-012-0229-3.
2. Rommens PM, Wagner D, Hofmann A. Surgical management of osteoporotic pelvic fractures: a new challenge. Eur J Trauma Emerg Surg. 2012. doi:10.1007/s00068-012-0224-8.

3. Rickman M, Young J, Bircher M, Pearce R, Hamilton M. The management of complex acetabular fractures in the elderly with fracture fixation and primary total hip replacement. Eur J Trauma Emerg Surg. 2012. doi:10.1007/s00068-012-0231-9.

4. Lehmann W, Hoffmann M, Briem D, Grossterlinden L, Petersen JP, Priemel M, Pogoda P, Ruecker A, Rueger JM. Management of traumatic spinopelvic dissociations: review of the literature. Eur J Trauma Emerg Surg. 2012. doi:10.1007/s00068-012-0225-7. 